\title{
JUSTIFYING MISTRANSLATION
}

\author{
Olivia Udo Ezeafulukwe* \\ http://dx.doi.org/10.4314/og.v15i1.8
}

\begin{abstract}
The eternal debate in translation circle, from the very first conception of its practice till date, has always been that of how identical a translated work should be to the original. Talks and debates about equivalence have not succeeded in telling us how identical a text should be to the original to qualify the version as faithful to the original. The debate has been so fierce that at different times lives have been lost even by people that are very knowledgeable in the field. Some translations adjudged faithful have been evaluated as unfaithful at some other circles leading to the belief that faithfulness and equivalence are all relative terms, understood in different ways by different people. This paper seeks to justify the so called unfaithfulness in certain translations by bringing to the fore the underlying information that provoke the so called mistranslation. It was discovered that translation being a human exercise cannot be perfect and that the word mistranslation in itself is a misnomer.
\end{abstract}

\section{Translation}

Translation as a practice has existed for so long and its origin can hardly be traced as it has long being used for interlinguistic and intercultural relationships. But as a discipline it can be said to have developed from the 1940's and 50's. Today translation has been discovered to be an interdisciplinary study involving studies in interculturality, linguistics, literary criticism, comparative literature, anthropology etc. For long, linguists have considered translation, not as a full-fledged discipline, but as an area of applied linguistics, or pragmatics while the mass communicators view it as an aid to communication. The result of several disciplines laying claim to translation has resulted to numerous, vague and sometimes conflicting and muddled up ideas as to what translation really is or the functions which it is expected to serve. This lack of precision has also affected the practice of translation as the translator is sometimes at a loss as of what is expected of him. 
Many attempts have been made to explain what translation is. Translation according to Jeremy Mundy could be viewed in the following three ways in the field of language viz:

(1) The general subject field or phenomenon ("I studied translation at the university")

(2) The product, that is the text that has been translated" they published the Arabic translation of the report")

(3) The process of producing the translation, otherwise known as translating("translation service") (8)

This present article is more concerned with the process of translation which Mundy went further to define as "the changing of an originally written text (the source text or ST) in the original verbal language (the source language or SL) into a written text (the target text or TT) in a different verbal language (the target language or TL)" (8)

But today's translation deals with much more than verbal texts hence O'grady et al view it as "taking texts written or spoken in one language and writing or speaking it in another."(610).This definition brings the oral part of translation, which is also referred to as interpretation, into play. But a wider view of translation was propounded by Roman Jakobson, where he described translation as being of three major forms:

(1) Intralingual translation, or rewording- an interpretation of verbal signs by means of other signs of the same language.

(2) Interlingual translation, or "translation proper"- an interpretation of verbal signs by means of some other language.

(3) Intersemiotic translation, or transmutation- an interpretation of verbal signs by means of signs of non-verbal sign systems. (139)

Translation is therefore both an interlingual and intersemiotic act aiming at passing a message expressed in one language (which could be oral, written or signed language) into another. 


\section{Mistranslation: Meaning and Causes}

Before we delve into the meaning and causes of mistranslation, it would be necessary to note that there is no perfect translation and that what some people consider as mistranslations are actually other forms of translation of the same text, which would be very welcome should they be presented in another target culture or target receivers.

\section{Mistranslation}

Mistranslation is a synonym of unfaithfulness or lack of fidelity. It is a misrepresentation of the author or the author's intention. There is mistranslation when a translation, which is aimed at unblocking a listener or reader fails to perform this function. Mistranslation could simply mean that the version has lost or gained information that was not in the original text. Mistranslation is a relative term. This is so because what could be seen as mistranslation to one group could be considered an excellent translation when offered to another group. A translation that is full of technical jargons of a particular profession could be seen as a faithful translation by people in the field who use such terms and terminologies in the day to day exercise of their functions. But such a translation would be worthless to a layman who cannot make out any meaning from it, even though it is written in a language he is supposed to be familiar with.

Though a language is usually a system of communication shared by a social group, but the extent of mastery and use of language differ from person to person, or from group to group and this is what Chomsky described as language competence and performance. And which Ferdinand de Saussure distinguished in his langue et parole/language and speech. These two phenomena also exist between the translator and the encoder of the message. A ST language could be improved or watered down by the activities of the translator due to his extent of performance in the TL and these two conditions could be interpreted as mistranslations in some circles.

Mistranslation can also depict an error in translation or the translation process. The diverse concepts of translation have evolved with them several recommended processes of translation, from the early process of word to word translation, linguistic translation, to the present meaning for meaning translation. The word for word translation which was the practice at the time when translation was mainly used for language teaching was considered the best form of 
translation but with translation delving into the area of religion, warranting the translation of holy books with the aim of making them accessible to people of different languages and cultures, it became imperative that meaning be transferred instead of words thus changing the purpose of translation.

Any translation that does not follow the trend of the time is considered a mistranslation or an unfaithful translation. During the era of word to word linguistic translation whoever did not conform to the norm was considered unfaithful. In the translation of Holy books the first set of translators who dared to change the original words of the Holy Book were accused of heresy and even lost their lives for the translations they made. One of such people was Etienne Dolet. In his 1540 manuscript la maniere de bien tradiuire d'une langue en aultre, Etienne Dolet has the following suggestions for a better translation;

(1) The translator must perfectly understand the sense and material of the original author although he (sic) should feel free to clarify obscurities

(2) The translator should have a perfect knowledge of both SL and TL, so as not to lessen the majesty of the language

(3) The translator should avoid word-for-word renderings.

(4) The translator should avoid Latinate and unusual forms.

(5) The translator should assemble and liaise words eloquently to avoid clumsiness.

(quoted by Bassnett 61)

Etienne Dolet, despite being very knowledgeable in the field of translation, lost his life as a result of his translation of some religious works into his autochthonous language, which was seen as heretical and unfaithful. Though he lost his life at the time but the fact remains that his translations remain masterpieces today that translators have adopted the transfer of meaning as the major objective of the translator. His works further highlighted the three levels of fidelity: faithfulness to the text (which implies faithfulness to the author), to the target language and to the receiver of the information.

Many $20^{\text {th }}$ century translation theorists also concur to these levels of fidelity. Jacques Flamand distinguishes three levels of faithfulness. In his words, translation means, "rendre le message du 
texte de départ avec exactitude (fidélité a l'auteur) en une langue d'arrivée correcte,(fidélité à la langue) authentique et adaptée au sujet de la destination (fidélité au destinataire)', (50)

"accurately rendering the message of the original text (faithfulness to the author) in a correct target language, (faithfulness to the language) authentic and adapted to the subject of the destination (faithfulness to the addressee)" (Our translation).

This goes to affirm that any translation that fails to put these three players into consideration (author, language and receiver) cannot be faithful. Consequently, the same translation could be adjudged unfaithful by one receiver who is knowledgeable and with a good thinking faculty but unfaithful to layman who would need more illustration and explanation to reach the text. A non -literay text has a characteristic of being intended for a particular user of group of users. Anyone outside the intended group may be lost even with a good translation of the document in his hands. A user guide of a drilling machine will naturally not make any sense to someone who is not in the field of drilling neither would words like megabite, data recharge and signing and logging in and out make much sense to someone that is not a computer literate.

Consequently, Nida posits that translation should aim at “...produire dans la langue d'arrivée l'équivalence naturelle la plus proche du message de la langue de depart, d'abord quant a la signification, puis quant au style (30) "Producing in the target language, the closest, natural equivalent to the source language text, first in meaning, then in style.(Our translation)

But this definition, though it has thrown more light into the very essence of present day translation, but it created new problems since it is difficult to understand what is considered a natural equivalent and what determines the equivalence that is closest. Every text causes an upsurge of meanings out of which the translator is expected to choose from. The context of the text might differ from the context of the translation and part of the translator's task is to contextualize the text for his own understanding and for the understanding of the receiver of his translation. It is possible that the meaning that the translator understood might be wrong as human acts are naturally full of imperfections. 
That same way, the decoder/receiver can decode a message that the translator did not intend to pass across as it is only from his wealth of experience that he can decode the new information.

For Newmark, translation involves "rendering the meaning of a text into another language in the way that author intended the text. (7) Of course every translator aims at transferring the author's intention. What is not easy, however, is to truly guess what the author's intention is. This entails first and foremost trying to understand the author. It is however true that what we call understanding is just an approximation of meaning. A translator actually translates what he understood from a text. At the process of translation there may not be feedback to the translator to tell him whether what he understood, which was encoded, was actually correct or wrong. As a result a translator might finish his work and go home happily expecting commendations for a work well done, only to discover, sometime later that what he understood and encoded was actually not the author's intention. Sometimes the translator never gets to know that there has been a misunderstanding of the author's intentions.

The case of oral translation, which is also called interpretation, is even more pathetic. The translation is done at the speed of speech and most often the speaker does not finish constructing the meaning before it is translated by the interpreter, At a certain point in the speech, the interpreter might realize that he has made a mistake in the earlier translations, but being that the speaker continues communicating at his natural speed, the translator does not find the time to correct his mistake.

The translator should not be blamed for this kind of mistranslation because he can only understand the author's intentions when they have been expressed and not before. But the construction of meaning is a gradual process which the situation of communication in the simultaneous and consecutive interpretations does not afford the translator the opportunity to follow to the end before re-expression.

Also some techniques in translation have been erroneously interpreted as mistakes and misinterpretations in translation. Vinay and Darbelnet; while listing their 7 translation techniques, discussed loan words as the very first technique. The translator is free to borrow words in their original text into the target text. This according to them is to cover up a deficiency that exists in the target 
language. But today's authors do not use loan words because the target language does not have an equivalent but rather to add local colour to the text and sometimes just as a touch of style or a show of their multilingual skill which is much sought after in the present world polity. A translator translating these loan words may in a bid to remain faithful to the style of the creator of the text, leave the loan words as they are in the original text, which to some target language readers would still remain incomprehensible, thus adjudging the translator as incompetent. But to some other group of readers who well understand the intricacies of literature or for the group of the better informed readers, the same translation condemned for not translating the borrowed words in the original would be acclaimed as a near perfect translation.

This further complicated the concept of mistranslation as one needs to understand whether a translator must remain faithful to the style of the author or is it just enough to translate his message? Can two people share exactly the same style of writing? Since words are culture dependent, can the style in a source language have exactly the same effect when imported or transferred into the target language? It is when clear and concise answers are given to these questions that one can now have better standard to judge whether a text has been faithfully translated or misinterpreted.

Translation is affected by space and time. In this era of globalization and with the present wave of multilingualism, people now live and interact together. Many cities of the world are now intercultural as they harbour human beings from all over the world. Hence, it is now almost impossible to find a monolingual community as it was of old. Languages that come in contact influence and modify each other. These modifications could be phonological, syntactic or morphological in nature. There is no language of the world that does not borrow words from other languages; the developed and underdeveloped languages alike.

Fromkin notes that "The English language has borrowed a lot. Of the 20,000 words that are in daily use, three fifth's are loan words." (474) O' Grady et al (300) throws more light into this assertion by 
Ezeafulukwe: Justifying Mistranslation

Table 1: Tabulating some English words and their origins.

\begin{tabular}{|l|l|}
\hline $\begin{array}{l}\text { Source } \\
\text { Language }\end{array}$ & Target Language \\
\hline Italian & motto, artichoke, balcony, casino, mafia, malaria. \\
\hline Spanish & $\begin{array}{l}\text { comrade, tonado, cannibal, mosquito, banana, guitar, } \\
\text { vigilante, marijuana }\end{array}$ \\
\hline German & poodle, kindergarten, senunar, noodle, pretzel \\
\hline Dutch & sloop, coleslaw, smuggle, gin, cookie, boom. \\
\hline $\begin{array}{l}\text { Slavic } \\
\text { languages }\end{array}$ & czar, tundra, polka, intelligentsia, robot \\
\hline $\begin{array}{l}\text { Amerindian } \\
\text { languages }\end{array}$ & $\begin{array}{l}\text { toboggan, opossum, wigwam, chipmunk, Ottawa, } \\
\text { Toronto }\end{array}$ \\
\hline
\end{tabular}

But it takes time before these borrowed words enter into the repertoire of a given language, hence a translator who utilizes them could be termed unfaithful today, but the same translator may not be considered unfaithful when the borrowed words enter the repertoire of the language of the target text.

To further buttress the spatiotemporal nature of translation Guidere reveals to us that "Translation always conforms to time and ideological evolution of its time." (51) (My translation) This being the case translation could as well have temporal or spatial undertone. It is not a secret that many new words find their way into a language due to the activities of translators and interferences due to languages in contact.

Adaptations of several forms have sometimes been interpreted as misinterpretations. Adaptation as a translation technique was listed by Vinay and Darbelnet as the 7th of the techniques of translation which include borrowing, calquing, literal translation, transposition, modulation, equivalent and adaptation. For the linguists adaptation can also be seen as substitution or cultural equivalence. They further explained that adaptation "s'applique à des cas où la situation à laquelle le message se réfère n'existe pas dans LA et doit être créée..."(52) ...comes into play when the situation referred to in the original text does not exist in the culture of the target text thereby necessitating some form of re-creation." (Our translation) 
Routledge Encyclopedia of translation (8) explains that

...adaptation encourages the theorists to look beyond purely linguistic issues and helps shed light on the role of the translator as mediator, as a creative participant in a process of verbal communication. Relevance, rather than accuracy becomes the keyword and this entails a careful analysis of the three major concepts in translation theory: meaning, purpose and intention (8)

What is traditionally understood as translation stays basically at the level of meaning, adaptation seeks to transmit the purpose of the original text, and exegesis attempts to spell out the intentions of the author.

Adaptation completely removes the translator from all the linguistic representations made by the originator of the message and leads him to an intersemiotic comparison from where the better suited situation and expression is selected for the translation. A reader seeing the proverb $A$ bon entenduer salut being translated as "A word is enough for the wise" might actually call it a mistranslation as such a reader might be looking out for linguistic equivalents of the words that constitute the original text.

Another area of concern as regards translation is in the area of machine translation. In a bid to help the translator to avoid mistranslation and remain faithful to the original, in this era of technology, man has designed ways of making tasks easy. The computer and machines have been designed and now used to ease the toils in the execution of tasks which at one time overwhelmed the translator. In the field of translation also, the story is not different. O' Grady intimates us that "Projects in machine translation in the 1940's and 1950's spawned much of the early research in computational linguistics.[...] Since computers are suited to tasks requiring memory, it would seem that, with careful programming, the problem of translating by computer could be solved.[...] but the problem turned out to be more difficult than was imagined.(610) Yes, it is true that massive amount of translated works were rolled out as every translated work is just some clicks away from the internet surfers. But the level of misinterpretation inherent in 
machine translation dampened the spirits of intending machine translators. Since the computer is not suited to tasks requiring memory, it would seem that with careful programming, the problem of translating by computer could be solved but the problem turned out to be more difficult than was imagined.

Despite this, machine translation cannot just be swept under the carpet due to the interlinguistic exchanges it has made possible and is still making possible. Today more money and attention is geared towards machine aided translations as the memory of the computer was not complicated enough to interpret the nuances of meaning which the extra linguistic communication adds to a text.

It remains a fact though that internet users benefit immensely from the volumes of machine translation they do online, at a very high speed and at little or no cost. Though the products might be imperfect, but they still give an overview of the texts and sometimes correct texts are also produced especially in technical and scientific translations.

Even when imperfections exist in the products of machine translation a post editing could be done by a human translator to take care of those aspects of the text which the machine could not process and therefore did not translate or mistranslated. Though it is also a fact that as long as humans continue to intervene in translation, it is impossible to rid it of imperfections which are only a human trait.

\section{Is Mistranslation Avoidable?}

The answer to this ominous question is "No". To start with, a clear conception of what misinterpretation entails is yet to be actualized. Does mistranslation have only to do with meaning or does it include the style of the original conceiver of the message? Should the receiver's person, context and expectation have anything to do with the meaning to transfer? It is said that he who pays the piper dictates the tune. The person who hired the translator also has his own purpose and intentions for hiring his services. Would the translation be said to be faithful if it does not satisfy the cravings of the person who pays for it?

In the translation circles the following clichés are common and well known; Traducteur est traitre, (meaning that the translator is a traitor) les belles traductions sont comme des belles filles (Beautiful translations are like beautiful women. When they are 
beautiful they are not faithful). There is this general belief that the translator is a traitor and cannot operate outside himself. The translator himself is a human being with his own nature, make up, orientation, perceptions of reality etc, just like his readers, and cannot remove his basic nature from his work.

Nida recognizes these difficulties that make absolute fidelity impossible when he wrote that "if we must insist on translation without any loss of information, therefore, not only translation, but also all communication whatsoever... may not take place without some loss (or gain) of information. The loss (or gain) of information is an integral part of the process of communication" (6)

The translator's world view, made up of his moral, ethical and philosophical principles and beliefs, affects the way he encodes and decodes every information that he receives and gives out. The worldviews of the translator, which include all the stereotypes and ethnocentric orientations, unconsciously affect every work a translator does. Because the stereotypes are formed in the subconscious they are not generally noticed and so are difficult to correct.

The world is always on the move, every day there are new discoveries. To every new discovery a new term or word is attached, hence the ever ceasing need to translate both the old and the new. The translator is supposed to be abreast with the new discoveries as they emerge, as well as find their equivalents in the languages that form his tools of operation. This for sure is a herculean task.

The translator is bound to always meet words, terms or phenomenon that he is not familiar with. But he does not want to show off his ignorance in this kind of situation. What he does is that he tries not to leave a communication gap. He therefore tries to close up the gaps using his personal imagination, which can sometimes fail.

At some other times, the translator's life is at stake. A text which was well accepted in a source culture might not be translated the same way in the target culture as it might have disastrous consequences on the receivers and even on the translator. The case of Salman Rushdie is a typical example. His book, Satanic verses which was published in Great Britain where it received the acclamation of the readers. The same book was however translated to other languages and these translations made the book available to greater number of readers including some Muslim readers, who did 
not receive the book well in their target culture as they saw the book as a threat to Islam. They, therefore, called for the death of Salman Rushdie. Three of his translators lost their lives due to their translations of this text and ever since Rushdie himself has been in exile under the protection of the queen. An attempt to save one's life can lure a translator into distorting the meaning of a text which he very well understood.

The role that translation plays in the popularization and sale of productions cannot be over emphasized. Many a time it is the writers of books or producers of articles that go in search of the translators to help them pass their intentions across to other tongues and cultures. The translator of choice is usually the translator that passes the message across in the best language, a language to reach the target, not just the one that passes the information the same way as the original conceiver did, but the one that embellishes and fine tunes the original work to meet the yearnings and demands of the target readers. That is to say that the translator is at liberty to bring in words, situations or contexts that are not the same as the original work. After all, the translator has severally been referred to as a cocreator with the author of the text that he is translating. Taking such liberties in translation is sometimes referred to as free translation or even adaptation. All these are permitted in the translation circles. Therefore accusing the translator of mistranslation when all these liberties are permitted does not make much sense.

It is also a known fact that no two languages are the same. Even languages from the same family possess some distinguishing factors which can manifest as morphological, phonological or even semantic differences. Even when the lexicon of the two languages seem similar as is the case of languages from one parent language, yet the meaning attributed to the words could differ in the two languages. A typical example could be seen in the false friends/faux amis where words that look alike are actually semantically different. Examples of such words are the English word "chance" and the French "chance" The two words, both of Latin origin have evolved to different meanings due to spaciotemporal influences. Such homographs can sometimes surge up as interferences during translation.

Interferences are natural upsurges in the speech of a bilingual or a multilingual and the translator can do absolutely 
nothing about them. A translator being a bilingual, will naturally have intermittent surge of linguistic interferences as the two languages will be affecting each other even without the translator realizing it. Little problems like the mispronunciation of certain words that exist in the two languages (e.g. attention [[ə ténsh'n] in English and [atâa $\bar{a}]$ in French), wrong semantic exchanges (e.g. reste which means remain in English and rest meaning stoping work in English), wrong orthographic renditions (such as realize/realise, specific/ specifique, distortion/ distorsion), wrong word transfer or wrong word formation (e.g *bilinguism in English instead of bilingualism. Such wrong word formation is caused by the similar word bilinguisme that is used in French. Another example is *Intranslatable used for untranslatable because of the French equivalent Intraduisible). Such mistakes are always noticed in the language of bilinguals.

The translator himself is an interlinguistic and intercultural mediator. The languages, which form his tool of operation, are fluid and not static as they keep evolving. Translating in a culturally diverse society and world is not easy because people look, act and think differently. Even within the same cultural area different world views are still prevalent. Cultural differences should be taken into account before encoding, decoding or interpreting messages. Translators who fail to realize that persons from different cultures may not look, think or act as they themselves do, run the risk of having those with whom they interact, judge them to be insensitive, ignorant or culturally confused and would also be tagged unfaithful translators.

Also, according to Teri Kwal Gamble and Michael Gamble:

During each interpersonal, small group or public communication, we all send and receive verbal and non verbal messages. What you talk about, the words you use to express your thoughts and feelings, the sound you make, the way you sit and gesture, your facial expressions and perhaps even your thought or your smell all communicate information... We send some messages purposefully... and some accidentally...Everything a sender or a receiver does or says is a potential message as long as someone is there to interpret the behavior. When you smile, frown, shout or 
whisper or turn away, you are communicating, and your communication is having an effect (10)

Sometimes the message which gets to the receiver may not be intentionally passed by the translator yet it is attributed to him and sometimes interpreted as misinterpretations. Even the mannerisms of translators can be interpreted as messages though the translator does not mean them to be.

The work of the translator which is to pass the message of the original text is a very complex one. Since communication always takes place in some context or setting, the translator, in a bid to transfer meaning is forced to marry the context of the original text and that of the target text. Every word, phrase and sign is weighed and compared alongside other possibilities that might exist. This exposes the translator to a lot of choices to make. The translator, as a human being, is bound to make mistakes sometimes even though he might have in mind to make the best choices.

The work of the translator being that of interlinguistic exchange also involves intercultural transfers. No two languages express reality in exactly the same way. Also the morphology of every language is developed to serve the realities of the host culture and so no language can develop above the society it serves. Every language is therefore deficient in one area or the other as it can only have words to describe the things in their various localities. A translator faced with such a situation can only make up the lacuna in the target language in any way he thinks best. Such additions are sometimes viewed with suspicion, though the translator is left with only two choices. Either to explain out the situation or leave it untranslated, which is even a greater evil. Languages of the same origin, serving people of the same level of development, are easier to translate from one another. This fact is further reiterated by Ijioma and Ezeafulukwe,

La traduction d'un texte d'une langue à une autre pose des problèmes au traducteur. Du surcroît, les défis de traduire d'une langue globalement connue et développée à une langue en voie de développement sont plus aigus. Chaque langue à des structures linguistiques différentes de celles 
d'autres langues et chaque langue a aussi sa propre manière d'exprimer la réalité.(193)

Translating from one language to another is problematic for the translator. In addition, the challenges of translating from a globally known and developed language to a developing language are more acute. Each language has linguistic structures different from others and each language also has its own way of expressing reality. (My translation)

The translator, in a bid to transfer meaning must sometimes subscribe to borrowing, direct translation, transposition, modulation, equivalents, adaptation, explanation, paraphrasing, compensation and even omissions. He must appropriate the text, that is, make it his, in content and in context before he can really re-express what he understood to someone else. These techniques when put into use, would sometimes make the translator not to express exactly the words of the originator of the message and so can be seen as misinterpretations.

The translator, though partnering with the originator of the message to construct meaning, is always working with texts produced by another. The texts, which could be written, oral or signed, are not perfect and sometimes possess inherent traits that make the work of the translator difficult. The original texts could have problems ranging from omissions, misconceptions, badly presented ideas, wrong perceptions, syntactical and stylistic challenges. It could as well be a text written a long ago causing a change in form, meanings and phonology attributed to words and sentences. The time lag could also result to changes which neither the translator, nor any person for that matter, can decipher easily.

It could well be a good text, but a text from an area of knowledge in which the translator is ignorant. Comprehension of the text is consequently problematic to the translator hence a difficulty in its transfer into another language. Sometimes the text before the translator is incomplete or a part of a bigger whole, a follow-up or a continuation of another work. It could well be that the shared knowledge which the first readers shared with the writer, that helped in the comprehension of the text, no longer exist. The translator is therefore obliged by situation to neglect this important part of meaning which he cannot lay his hands on. One would therefore not 
expect the best from such situation as the translator can only work with the materials at his disposal.

At some other times, the text which the translator seeks to translate is not an original work but a translated work. Some of these texts have been translated, twice, thrice or even more times and the translator cannot lay his hands on the original text or is not familiar with the original text and so cannot use it, even when it is at his disposal. As a text moves from one language into another and from one translator to another, it gains a lot of information and loses some information too. Thus the text in the hand of the last translator might have undergone a lot of distortions and transformations, which the translator does not know about and so makes no effort to correct.

Also, some texts have inherent natures that make their translation difficult. The case of poetry and technical translations is an example. Due to the rimes and rhythms of poetry, it is a difficult area to translate. Whereas some translate poems into prose as they aim at the translation of the content, others prefer not to translate poetry at all since the sound effect which is sometimes the objective of the poem is lost in translation. Acronyms and abbreviations cannot be translated without changing their original forms. Technical texts also demand the knowledge of the jargon of specific areas of knowledge which the translator may not be conversant with. The translator, even when at home with the jargons of the area may find such technical and specialized language difficult to explain to a layman who could be the recipient of his translation. An attempt to water the translation down to the level of the translator's receiver may water down the language of the text.

In this era of globalization, a lot of exchanges are taking place. The translator, being at the centre of the linguistic exchanges, is always on his toes to bridge the linguistic gap arising from information from other languages and cultures. The limited time at the translator's disposal, the enormous volume of work to be translated, the unavailability of necessary gadgets to ease translation difficulties, pose real problems to the translator and affects his productivity and quality of translation resulting in what is sometimes termed unfaithful translations. 


\section{Conclusion}

Mistranslation is unavoidable in translation. To start with the word mistranslation is a relative term understood differently by different people to mean different things in different settings and times. What is termed a mistranslation today may well become a faithful translation with the passage of time when the lexicology of the target language accepts the words used in the translation. Also, the same translation could be adjudged near perfect by an expert in the field but unfaithful by the receiver who lacks knowledge in the area and so cannot understand the basic jargons.

Due to cultural differences and taboos, an otherwise good translation might be faulted due to the circumstances of the target culture. Some words are not freely used in some cultures and some realities are also not discussed in the open, certain discussions are gender sensitive and any attempt to go against these norms, by the translator is vehemently opposed.

Translating, being a human activity, cannot be rid of imperfections. Even when it is a machine translation, the machine still works with language and language is a human system. Information is fed into the computer by humans and so accuracy in machine translation is also not assured.

A lot of things come into focus when considering whether a text has been misinterpreted or not. One should first of all define what is meant by mistranslation, a term that is not uniformly understood. It is not yet settled whether it should be understood to mean only a lack of translation of the author's intention, his language, his style or just not considering the final target reader/audience,

Since every human text is an embodiment of linguistic and cultural realities and carries a lot of the idiosyncrasies of the original conceiver, it is quite impossible to translate exactly the original text, a text developed by a different individual and in a language different from the target language.

*Olivia Udo Ezeafulukwe, PhD, Department of Modern European Languages, Nnamdi Azikiwe University, Awka - Anambra State, Nigeria olyvconnect@yahoo.com/ezeafulukwe.ou@unizik.ng 


\section{Works Cited}

Ajunwa, Enoch. A Textbook of Translation Nigeria: Enovic Ltd, 2014.

Bassnett, Susan. Translation Studies. $3^{\text {rd }}$ ed. London: Routledge, 2002.

Chomsky, Noam. Aspects of Theory of Syntax. Cambridge: MIT Press, 1965.

Flamand, Jacques. Ecrire et traduire sur la voie de la création. Ottawa: Vermillon, 1983.

Fromkin, Victoria. An Introduction to Language. $8^{\text {th }}$ Ed. United States: Thomson/ Wadsworth, 2005.

Gamble Teri Kwal and Gamble Michael. Communication Works. New York: Mcgraw-Hill, 2012.

Guidere, Mathieu. Introduction à la traductologie: penser la traduction : hier, aujourd'hui, demain. Bruxelles : De Boeck Supérieur, 2010.

Ijioma Ngozi and Ezeafulukwe Olivia. "Translating Technical Tests: the Igbo Language Example" the Nigerian Linguists Festchrift. No.12, 2015(193-202)

Jeremy Munday Introducing Translation Studies: Theories and Applications 3rd edition New

York: Routledge. 2004.

Newmark, Peter. Approaches to translation. New York: Pergamon Press, 1981.

Nida, Eugene et Taber Charles. The Theory and Practice of Translation. Leiden: E.J. Brill,1969

O' Grady, William et al. Contemporary Linguistics: An Introduction. Second Edition. London: Pearson Education Ltd, 2011.

Salman Rushdie. The Satanic Verses. United Kingdom: Dewey Decimal, 1988.

Vinay Jean et Darbelnet Jean, Stylistique comparée du français et de l'anglais. Didier : Paris, 1977. 